
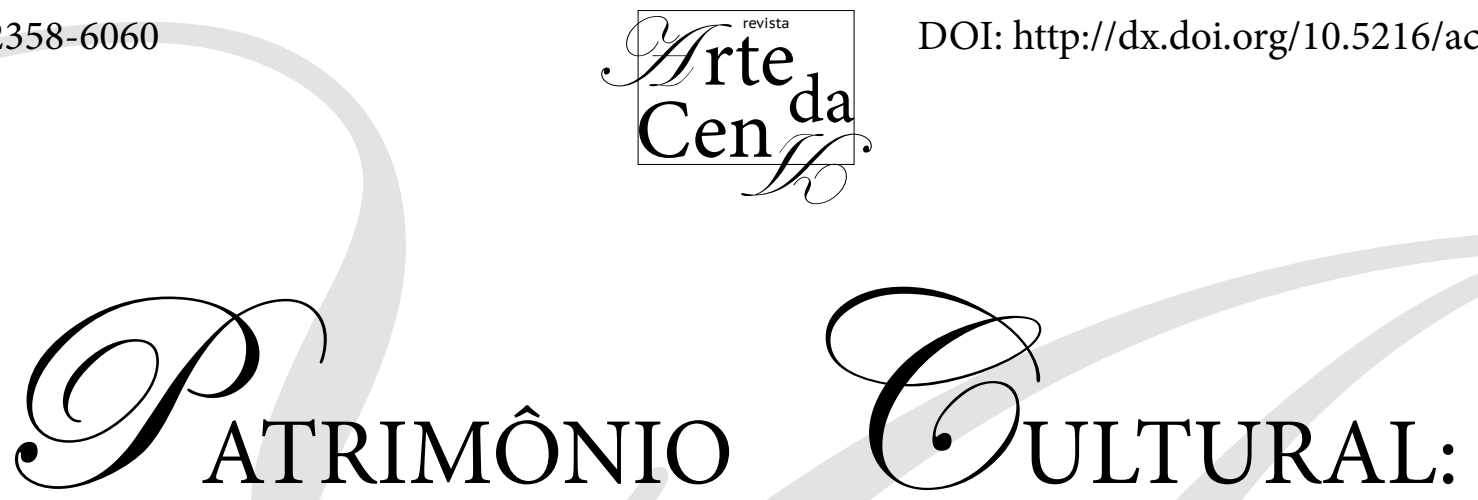

\title{
UMA COLABORAÇÃO PARA A CONSTRUÇÃO DA CIDADANIA DE UM POVO
}

"Cultural Heritage:

A collaboration for the construction of the citizenship of a peaple"

Ednair Rodrigues Nascimento*

Diretora do Museu Estadual de Rondônia

Professora das Faculdades Integradas Aparício Carvalho

e Faculdade São Lucas

RESUMO: No presente artigo faz-se uma reflexão sobre o papel do patrimônio cultural como colaborador na construção da cidadania, por meio da valorização dos patrimônios paleontológicos e arqueológicos. Foram elaboradas oficinas pedagógicas com professores e crianças de uma escola da Zona Rural no município de Porto Velho. Com as ações de educação patrimonial pôde-se resgatar e fomentar a cidadania uma vez que a paleontologia busca entender os ambientes pretéritos e as relações dos seres com o meio e a arqueologia busca reconstruir a história de um povo.

Palavras-chave: Patrimônio Cultural; Arqueologia, Paleontologia; Cidadania; Educação Patrimonial.

ABSTRACT: In this paper is a reflection about the cultural heritage like colaborater in the constrution of the citizenship, through the increase value of the paleontologic and archeologic heritage. Went elaborated educational workshops with teachers anda children in a rual school in the Porto Velho city.. With the actions of the heritage Education was possible to rescue anda Foster citizenship since paleontology seeks to undersstand the past tense environments anda relations of beings with the environment and archeology seeks to reconstruct the history of the peaple.

Keywords: Cultural Heritage; Archeology; Paleontology; Citizenship; Heritage Education 


\section{Introdução}

Quando falamos em patrimônio, temos a tendência de pensar em um bem material e de certo valor econômico (ROCHA, 2012). Esse pensamento é normal, porém muito reduzido, pois minimiza o conceito da palavra patrimônio, principalmente quando a mesma está agregada a palavra cultural. Outro conceito que provem da área jurídica familiar, segundo Castelo Branco (2008) é o princípio relacionado ao bem de herança que é transmitido, segundo as leis, dos pais e das mães aos filhos, sendo uma palavra repleta de simbolismo. Neste sentido o Patrimônio Cultural é uma expressão contemporânea, amplifica este significado indo além, expressa a produção de bens materiais e imateriais feitos pela a humanidade em tempos pretéritos e atuais, sendo o resultado de experiências e memórias e vivências individuais e coletivas. No entanto, pode-se dizer que o Patrimônio Cultural remete-se a uma herança cultural, partindo das lembranças individuais que ganham significado e constroem as lembranças de um grupo. Além disso, o Patrimônio Cultural remete a semente de rememoração, ao pertencimento e o encontro com algo que desperta sentimentos e lembranças significativas de um povo e de uma época, levando a compreender a sociedade por meio de seus objetos e suas representações.
Sendo assim o patrimônio cultural dividise em dois grandes caminhos, o Patrimônio Cultural Material e o Patrimônio Cultural Imaterial. Segundo o Instituto do Patrimônio Histórico Nacional - IPHAN o Patrimônio Cultural Material se refere a toda obra construída pelo homem de características histórica e social, podendo ser arquitetônica ou edificada, arqueológica, paleontológica, artística, religiosa e da humanidade. Desta forma com a materialidade, o indivíduo consegue se realizar e afirmar sua identidade cultural, podendo também, reconstruir seu passado histórico (OLIVEIRA; LOURES OLIVEIRA, 2008).

De acordo com a Convenção para a Salvaguarda da UNESCO de 2003, o Patrimônio Cultural Imaterial refere-se "as práticas, representações, expressões, conhecimentos e técnicas, junto com os instrumentos, objetos, artefatos e lugares que lhes são associados - que as comunidades, os grupos e, em alguns casos, os indivíduos reconhecem como parte integrante de seu patrimônio cultural. Este Patrimônio Cultural Imaterial, que se transmite de geração em geração, é constantemente recriado pelas comunidades e grupos em função de seu ambiente, de sua interação com a natureza e de sua história, gerando um sentimento de identidade e continuidade, contribuindo assim para promover o respeito à diversidade cultural e à criatividade

Ednair Rodrigues Nascimento - Patrimônio Cultural: Uma colaboração para a construção da cidadania de um povo Revista Arte da Cena, Goiânia, v. 2, n. 2, p. 98-104, Jan.-Jun./2016 
humana”.

Para Rocha (2012), o patrimônio possui a capacidade de estimular a memória das pessoas historicamente vinculadas a ele, por isso, é alvo de estratégias que visam a sua valorização e preservação.

Em vista disso, sua promoção tornase fundamental no que diz respeito ao desenvolvimento cultural de um povo, uma vez que reflete em sua formação sociocultural.

\section{Patrimônio Cultural e a construção da cidadania}

Segundo Pelegrini (2008), ao se falar em patrimônio cultural imediatamente associa-se o termo aos conceitos de memória e identidade, "uma vez que entendemos o patrimônio cultural como lugarprivilegiado onde as memórias e as identidades adquirem materialidade". Edificações históricas e os museus convergem a essa definição de lugares de memórias e valorização das identidades que compõem uma sociedade. Uma vez que bens culturais são preservados e valorizados as identidades culturais são fortalecidas e promovendo o desenvolvimento cultural.

Segundo Halbwanchs (1990), a memória deve ser compreendida também, como um fenômeno coletivo e social. Esse fenômeno é representado nos lugares que recebem a marca de um grupo e a presença deste grupo deixa a marca nesses lugares, sendo assim chamados lugares de memórias. Esses lugares despertam a identidade, as lembranças e as relações criadas nesses espaços. Uma sociedade que preserva seus espaços históricos e suas relações que se constroem nesses espaços leva ao outro a oportunidade de reviver as experiências mantendo a "memória viva" (RO. Neste sentido, a identidade cultural cria vínculos e leva a construção da cidadania e ao desenvolvimento cultural. A construção da cidadania por meio do patrimônio cultural ocorre quando o individuo reconhece seus bens culturais com a valorização e preservação, criando políticas públicas que promovam esses patrimônios, vivenciando no presente e transmitindo as gerações futuras.

Mas de que modo isso pode ser feito? Esse é um questionamento feito por muitos defensores do patrimônio cultural, especialmente quando algum patrimônio encontra-se em risco. Nesse sentido o processo educativo é o ponto norteador para o resgate e a preservação de um patrimônio cultural, conhecido como a Educação Patrimonial que visa à valorização do patrimônio cultural. A Educação Patrimonial hoje no Brasil tem sido bem difundida devido a proeminência dos estudos arqueológicos, visto que a educação 
patrimonial nunca pode ser dissociada de um estudo arqueológico, pois esse processo educativo que cria ligações com as comunidades circundantes aos sítios arqueológicos. Já que muitas regiões do país apresentam um processo de pós-colonial bastante recente e contrapondo as ocupações pré-coloniais. Assim programas educativos são realizados e conjunto com os levantamentos arqueológicos, sendo feito geralmente de forma informal, com os moradores locais e com estudantes das escolas da área de influencia dos estudos. As ações educativas geram o reconhecimento e a valorização das identidades culturais por meio da representação dos objetos arqueológicos e fósseis, levando a compreender as relações humanas pretéritas, promovendo a socialização e a apropriação colaborando na preservação deste bem cultural, caracterizando uma ação de cidadania.

\section{Educação Patrimonial uma experiência por meio Patrimônio Arqueológico e Paleontológico}

A Educação Patrimonial tem sido considerada como um ensino focalizado nos bens culturais, e tem como objetivo proporcionar a comunidade, principalmente as crianças, um contato maior com o patrimônio cultural da sua região. Com ela, busca-se levar crianças e adultos a um processo de conhecimento e valorização do universo sócio-cultural da comunidade, o que acaba por capacitá-los a usufruir, de maneira correta, estes bens.

Será relatada aqui a experiência do Projeto de Educação Patrimonial em escolas de ensino fundamental da Zona Rural de Porto Velho - Rondônia. A finalidade do projeto foi proporcionar ao público alvo elementos para as reflexões acerca do conhecimento adquirido a partir das pesquisas que são desenvolvidas na região, voltando-se principalmente para aqueles alcançados com o patrimônio arqueológico e paleontológico. O projeto foi desenvolvido na zona rural ribeirinha de Porto Velho, nas escolas atingidas pela construção da Usina Hidroelétrica de Santo Antônio, localizada no Rio Madeira.

Os procedimentos metodológicos adotados para o desenvolvimento do projeto consistiu em oficinas educativas, exposição de materiais arqueológicos e paleontológicos por meio de aulas e práticas com as crianças e professores. As oficinas foram desenvolvidas em cinco módulos.

No primeiro módulo, trabalhou-se com os professores uma oficina de capacitação sobre os patrimônios arqueológicos e paleontológicos, bem como foi realizada uma análise dos livros didáticos e dos currículos a fim colaborar no melhor ensino desses conteúdos em sala de aula de forma transversal e multidisciplinar. 


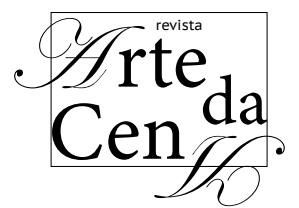

DOI: http://dx.doi.org/10.5216/ac.v2i2.43679

No segundo modulo trabalhou-se com a história da região, com ênfase na paisagem e no legado indígena e ribeirinho, destacando a sua importância para a formação sociocultural. O objetivo centrou-se em levar as crianças a perceberem o quão recente foi à ocupação da região e problematizar as consequências de tais fatos. No final da aula as crianças realizaram atividades pedagógicas de acordo com as faixas etárias.

Na terceira etapa, ficando pactuada com os professores, no primeiro módulo, a aplicação dos conteúdos aprendidos na oficina em sala de aula, sendo que os mesmos realizaram atividades com as crianças. Sendo uma atividade motivada pelos professores da escola, sem a participação da equipe.

$\mathrm{Na}$ quarta etapa a equipe retornou a escola com uma exposição de fósseis e artefatos arqueológicos coletados na região, com a participação de monitores e mediadores didáticos. A exposição foi montada no pátio da escola, sendo assim houve uma conversa prévia com as crianças ainda em sala de aula, e as mesmas apresentaram textos e desenhos das atividades realizadas pelos professores. Em algumas turmas, os professores fizeram varais de leitura com os textos e desenhos elaborados pelas crianças, bem como os professores entregaram os planos de aulas do conteúdo aplicado em sala. A visita a exposição foi realizada por turma em que os alunos tiveram a oportunidade de ver o material coletado na região. Todas as turmas visitaram exposição e foram participativos por meio de questionamentos e partilha de suas histórias e experiências.

E por fim, a escola fora convidada para uma visita ao laboratório onde o material coletado estava sendo analisado, uma vez que as coletas já haviam sido realizadas na localidade. As crianças foram conduzidas ao laboratório e assim puderam ver como todo conhecimento é gerado por meio dos estudos.

Os textos e desenhos foram dados a equipe e com o material pode-se analisar e conforme Oliveira (2010) diz: “após a leitura e interpretação do material apresentado, podemos destacar os efeitos positivos das ações de extensão, na medida em que proporcionamos às crianças, instrumentais para iniciativas de valorização enquanto atores, diretos ou indiretos, do processo de construção dos saberes”.

Vale ressaltar que todos os textos e desenhos expressaram os aspectos de pertencimento aos lugares de memórias, uma vez que o público alvo, professores e alunos, passaram por um processo de impacto, por conta da implantação de uma 


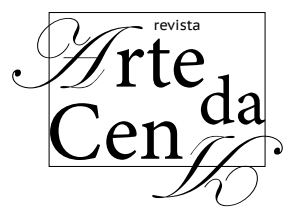

DOI: http://dx.doi.org/10.5216/ac.v2i2.43679

hidroelétrica e por isso sofreram deslocamento de suas moradias e escola, já que a localidade foi inundada pelo reservatório. Neste sentindo, a representação do patrimônio paleontológico e arqueológico por meio das oficinas resgataram a dignidade e colaboraram na construção da cidadania local.

\section{Considerações Finais}

O estudo do patrimônio cultural, da memória e da identidade são elementos importantes na valorização e preservação bem como colaboram na construção da cidadania, levando o individuo a compreender seu papel de agente social na sociedade, em particular do patrimônio arqueológico e paleontológico. Uma vez que a paleontologia busca entender os ambientes pretéritos e as relações dos seres vivos com o meio e a arqueologia busca reconstruir a história de um povo.

Através deste processo de construção de identidades culturais, pode-se chegar a uma real formação de comunidade que se reconheça com afinidades de presente e passado, de modo que podemos manter os indivíduos próximos, e é neste aspecto que a questão dos marcos referencial, dado pelo patrimônio arqueológico e paleontológico, contribui para a consolidação das identidades e levam à conscientização do papel social desenvolvido pelo indivíduo perante a sociedade (KRAISH, 2007).

A partir do momento em que se começa a discutir e compreender a importância de se preservar a memória e a história de um povo começa a se constituir o senso de cidadania, e as autoridades começam a se articular na concretização da preservação destes lugares de memórias, por meio de fomento e políticas públicas. É interessante perceber que isso é um movimento coletivo, mas que parte do individual, e nesta questão que a educação patrimonial é essencial, pois possibilita essa aproximação da sociedade e seu patrimônio.

A Educação Patrimonial acaba promovendo uma transformação na maneira de se ver e tratar a cultura e busca um aprimoramento nas formas de repassar para o publico leigo, as descobertas cientificas, ao ser aplicado em comunidades próximas a patrimônios reconhecidos, como sítios arqueológicos e paleontológicos, assim como em escolas, visando sensibilizar sobre a importância do reconhecimento, da valorização e da conservação do patrimônio da região (ROCHA, 2012).

Ednair Rodrigues Nascimento - Patrimônio Cultural: Uma colaboração para a construção da cidadania de um povo Revista Arte da Cena, Goiânia, v. 2, n. 2, p. 98-104, Jan.-Jun./2016 


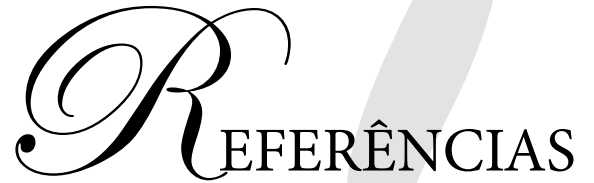

CASTELO BRANCO, P. M. Patrimônio histórico e turismo:Uma construção social. 2008. (Disponível em:www.iphan.gov.br)

HALBWACHS, M. A memória coletiva. São Paulo: Vértice, 1990.

KRAISH, Adriana M. P. O. O Patrimônio arqueológico como elemento doPatrimônio Cultural. In: ANPUH, 2007.

OLIVEIRA, Luciane Monteiro; LOURES OLIVEIRA, Ana Paula de Paula.Problemáticas da Gestão do Patrimônio e Políticas Públicas: A educação na perspectiva de mudança paradigmática. Juiz de Fora, 2008.

OLIVEIRA, Luciane Monteiro; LOURES OLIVEIRA, Ana Paula de Paula. Criação, experiência e manipulação do conhecimento revelado nos registros gráficos de crianças. In: LOURES OLIVEIRA, A. P. P; OLIVEIRA, L. M. (Org.) Arqueologia epatrimônio de Minas Gerais: Ouro Preto. Juiz de Fora: Ed. UFJF, 2010.

PELEGRINI, Sandra C. A. Cultura e natureza: os desafios das práticas preservacionistas na esfera do patrimônio cultural e ambiental. In: Revista Brasileira de História. São Paulo 2006, v. 26, no 51, p. 115-140.

ROCHA, T. S.F. Refletindo sobre memória, identidade e patrimônio: as contribuições do programa de Educação Patrimonial do MAEAUFJF. In: ANPUH, 2012.
* EDNAIR RODRIGUES NASCIMENTO possui mestrado em Geociências, na área de concentração em Paleontologia, pela Universidade Federal do Rio Grande do Sul UFRGS (2008). Possui licenciatura e bacharelado em Ciências Biológicas pela Fundação Universidade Federal de Rondônia - UNIR (2004). Atualmente é paleontóloga e diretora do Museu Estadual de Rondônia (Secretaria de Cultura do Governo de Rondônia), e professora das Faculdades Integradas Aparício Carvalho e Faculdade São Lucas na cidade de Porto Velho. Apresenta experiência na formação de professores, Paleontologia e Patrimônio Cultural. E-mail: ednair.nascimento@gmail.com

Ednair Rodrigues Nascimento - Patrimônio Cultural: Uma colaboração para a construção da cidadania de um povo Revista Arte da Cena, Goiânia, v. 2, n. 2, p. 98-104, Jan.-Jun./2016 